\title{
Tumor de Evans de la mano. Una localización excepcional
}

\author{
P. Sánchez Gómez ${ }^{(1)}$, J. F. Soler Gutiérrez ${ }^{(2)}$, J. A. Lozano Requena ${ }^{(3)}$, \\ J. A. Ruiz MaCia ${ }^{(4)}$
}

Hospital VeGa BAJA DE ORIHUELA

${ }^{(1)}$ MÉDICO INTERNO RESIDENTE

${ }^{(2)}$ FACULTATIVO ESPECIALISTA ÁREA

(3) JEFE SERVICIO COT

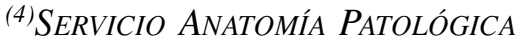

Correspondencia:

Dr. Plácido Sánchez Gómez

C/ República Dominicana 4 Bajo Izquierda

30530 Cieza. Murcia

Tel.: 626905636

e-mail: placidosanchezgomez@yahoo.es

Introducción. El sarcoma fibromixoide de bajo grado es un sarcoma de partes blandas caracterizado por un curso clínico y una histología aparentemente benigna, pero que puede dar recidivas locales y metástasis a distancia. La cirugía constituye el tratamiento de elección.

Caso clínico. Varón de 30 años que presenta tumoración indolora en eminencia tenar mano izquierda de 12 meses de evolución. En la primera exploración se aprecia un nódulo duro y fijo en región tenar izquierda, que en la resonancia magnética con contraste se localizaba a la altura de la base del primer metacarpiano con captación heterogénea de contraste. La punción aspirativa con aguja fina es compatible con tumor mesenquimal, por lo que se opta por un tratamiento quirúrgico de conformidad con el paciente. El estudio anatomopatológico definitivo establece el diagnóstico de sarcoma fibromixoide de bajo grado sin infiltración tumoral de los bordes quirúrgicos y estudio de extensión negativo. Al año de control clínico, no existen indicios de recidiva tumoral, ni local ni a distancia. La presentación superficial, en extremidades superiores o en edad pediátrica es excepcional.

Palabras clave: Tumor Evans. Sarcoma Fibromixoide. Tumor Mesenquimal. Sarcoma partes blandas.
Introduction. Low-grade fibromyxoid sarcomas are uncommon deep soft tissue neoplasms first described by Evans in 1987. They exhibit a deceptively benign appearance, with a whorled or linear arrangement of spindle-shaped cells showing few to absent mitoses. A characteristic, but not specific, feature is the presence of areas of myxoid stroma. Recurrences are common, and late metastases have been recorded. Surgery is the election treatment. Clinical case. A 30-year-old man presented with a year history of a painless slow-growing mass in the left hand. In the first exploration a hard and fixed nodule is appraised in the left first metacarpal bone. Magnetic resonance images were obtained demonstrating a well defined mildly heterogeneous soft tissue mass of intermediate signal intensity. A pre-operative fine needle aspiration was a suspicion of mesenchymal tumor. The tumor was diagnosed as low grade fibromyxoid sarcoma. Immunohistochemistry was performed to confirm the diagnosis. The patient had no evidence of local recurrence or metastases after a year of follow-up. Low-grade fibromyxoid sarcoma (LGFMS), usually a deeply situated mass in adults, is uncommon in superficial soft tissue, upper extremities and in children.

Key Words: Evans tumor, low-grade fibromyxoid sarcoma, mesenchymal tumor, soft tissue neoplasms. 


\section{INTRODUCCIÓN}

El sarcoma fibromixoide de bajo grado (SFMBJ), descrito por Evans en $1987^{1}$, es un tumor de partes blandas infrecuente caracterizado por un curso clínico y una histología aparentemente benigna, pero que puede dar recidivas locales y metástasis a distancia. Afecta, preferentemente, a adultos jóvenes, con un ligero predominio del género masculino. Su localización más frecuente es en el muslo, la región inguinal y el hombro, siendo la presentación superficial, en extremidades superiores o en edad pediátrica excepcional ${ }^{2}$. El tratamiento de elección es la cirugía.

\section{CASO CLINICO}

Varón de 30 años, sin antecedentes de interés. Acudió a consulta de Cirugía Ortopédica y Traumatología por presentar, desde hace un año, una tumoración indolora en la región de la eminencia tenar izquierda. La lesión coincidía en espacio y tiempo con la aparición de un hematoma tras caída practicando deporte. En la exploración se apreciaba nódulo de consistencia dura y fija en la región tenar izquierda (Figura 1). La resonancia magnética $(\mathrm{RM})$ con contraste (Figura 2) mostraba una lesión que se localizaba medial a nivel de la base del primer metacarpiano entre el músculo aductor del pul-

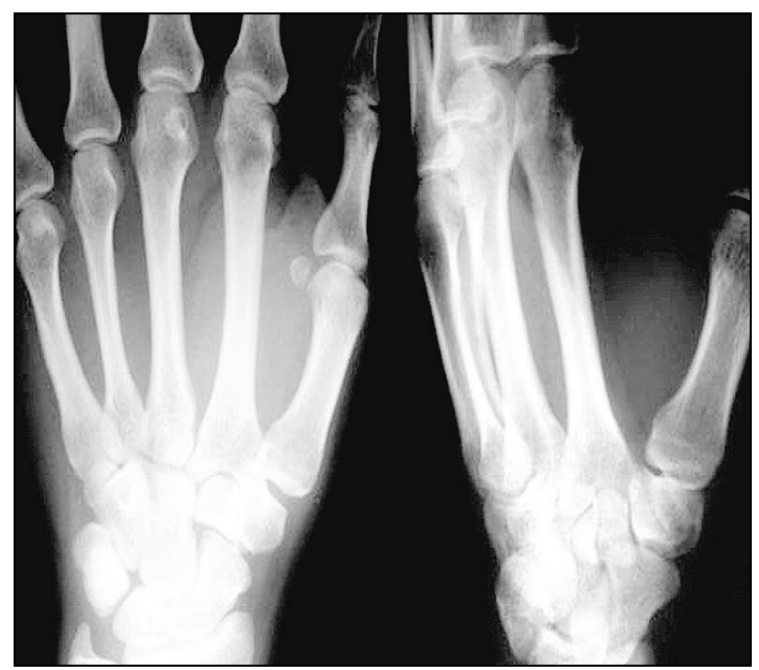

Figura 1. Imágenes de radiología simple donde puede apreciarse la no afectación ósea y el aumento de partes blandas en la eminencia tenar.

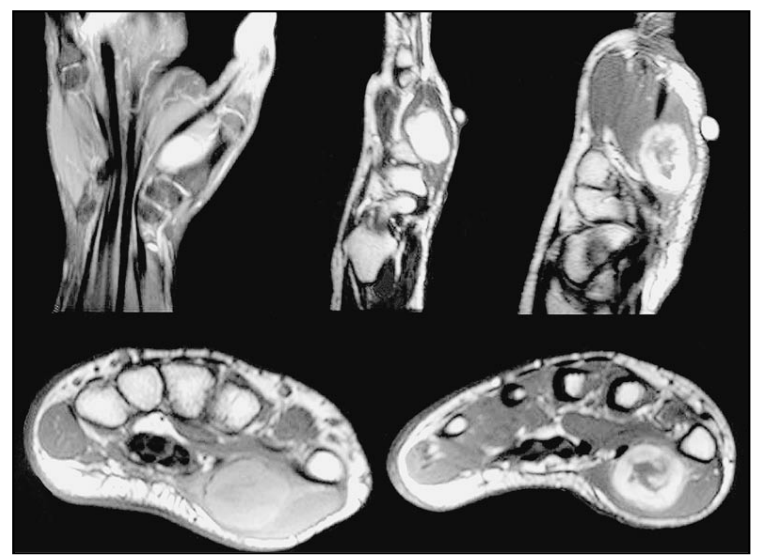

Figura 2. Imágenes de resonancia magnética: lesión redondeada de unos $2 \mathrm{~cm}$. bien delimitada entre el músculo aductor y el flexor corto del pulgar que desplaza al tendón del músculo flexor largo sin afectar su vaina ni las estructuras óseas adyacentes.

gar y el músculo flexor corto. Desplazaba la vaina tendinosa del músculo flexor largo del pulgar, sin provocar una alteración de su señal. No se apreciaban alteraciones en la señal de la médula ósea en vecindad de la lesión. La masa parecía bien delimitada con captación neta y heterogénea del contraste y una zona central no captante. Aunque no se podía precisar la naturaleza de la masa, se descartó en la exploración por la imagen que se tratase de quiste, hemangioma, aneurisma, lipoma, hematoma, tumor neurológico o mixoma muscular; se estableció como diagnóstico más probable el de tumor de estirpe fibrosa. El estudio anatomopatológico mediante punción aspiración con aguja fina (PAAF) fue compatible con un tumor mesenquimal benigno, decidiendo, de conformidad con el paciente, su exéresis quirúrgica por el rápido crecimiento y el perjuicio estético.

En la intervención se encontró una masa en el espesor del músculo flexor corto del pulgar dura y redondeada de aproximadamente $2 \mathrm{~cm}$., que se liberaba bien de estructuras adyacentes, con un aparente buen plano de separación; efectuándose una exéresis marginal a través de la seudocapsula (Figura 3).

El estudio anatomopatológico (Figura 4) e inmunohistoquímico del tumor reveló la existencia de áreas fibrosas y mixoides con células fusiformes, que exhibían núcleos ovales de cromatina finamente distribuida y nucleolo poco evidente. No se observaron mitosis, necrosis, ni áreas hemorrágicas y por fuera de la seudocáp- 


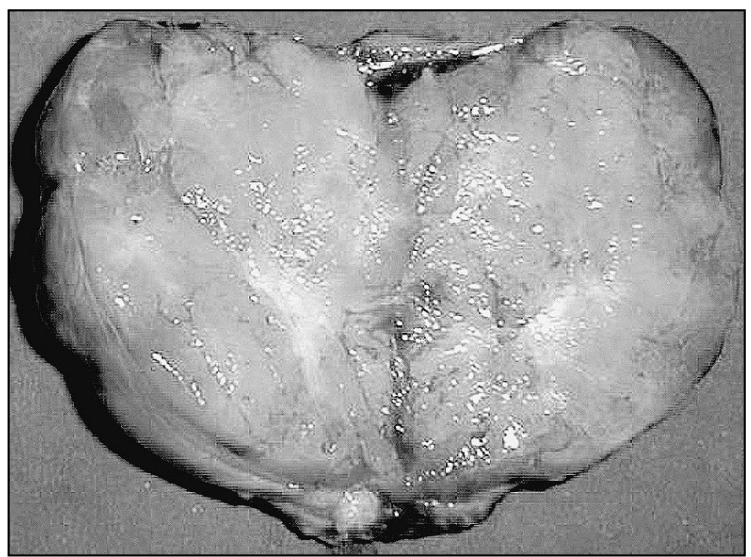

Figura 3. Imagen macroscópica (cortada transversalmente): tumoración circunscrita de bordes bien definidos (seudocápsula) y con una superficie de corte amarillo grisáceo, firme y fibrosa, que contiene áreas mixoides focales.

sula había una banda de músculo estriado sano de 1-2 mm. La Ki 67 es positiva en el 5\%, siendo la desmina, actina, S-100, EMA, Bcl 2 y CK 7 negativos. El diagnóstico definitivo fue SFMBJ (tumor de Evans) con márgenes de resección libres.

El estudio de extensión (Tomografía axial computerizada de tórax y de abdomen, y gammagrafía ósea) descartó la presencia de metástasis, por lo que se decidió no administrar tratamiento radioterápico ni quimioterápico postoperatorio, ante la extirpación tumoral completa con márgenes libres sin enfermedad a distancia objetivada.

La revisión al año, clínica y mediante Tomografía axial computerizada de tórax y RM seriadas no ha mostrado indicios de recidiva local o diseminación a distancia.

\section{DISCUSION}

El SFMBJ es un sarcoma de partes blandas infrecuente, con rasgos histológicos de bajo grado y curso clínico paradójicamente agresivo, conocido también como "tumor de Evans" pues fue este autor quien lo describió en $1987^{1}$. A excepción de un caso aislado, no se publicaron más casos hasta 6 años después de la descripción original, cuando dicho autor comunica 10 casos más. En 1993 se establece la existencia del SFMBJ como una entidad aislada ${ }^{2}$.

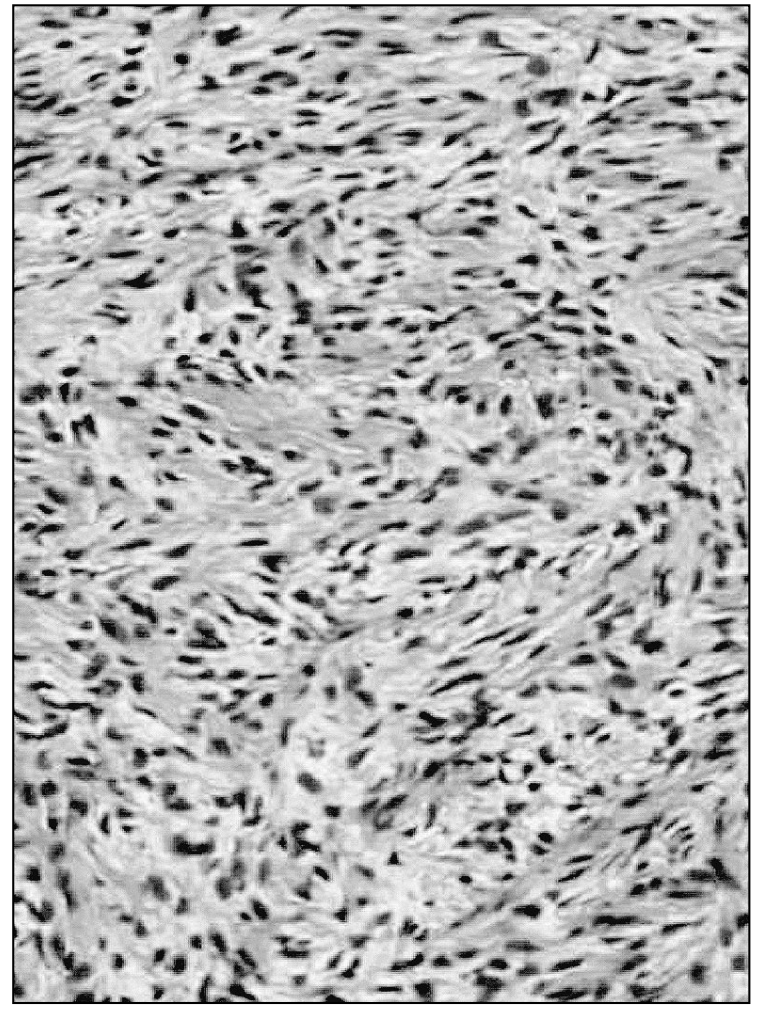

Figura 4. Imagen microscópica: existencia de áreas fibrosas y mixoides con células fusiformes con núcleos ovales de cromatina finamente distribuida y nucleolo poco evidente. No se observaron mitosis, necrosis, ni áreas hemorrágicas y por fuera de la seudocápsula había una banda de músculo estriado sano de 1-2 mm. La Ki 67 es positiva en el 5\%, siendo la desmina, actina, $S$ 100, EMA, Bcl 2 y CK 7 negativos.

En su artículo original ${ }^{1}$, Evans presentó dos casos, que afectaban a mujeres, con un tumor de partes blandas localizados en la región escapular y en la pared torácica, respectivamente. Ambos se trataron exclusivamente con cirugía, con desarrollo de metástasis pulmonares tardías en una de ellas, mientras que en la otra ya se presentaban en el momento del diagnóstico. La primera paciente falleció a los 94 meses de la cirugía y la segunda a los 82 .

Los 10 casos adicionales publicados en $1993^{2}$ presentaban otras localizaciones: región inguinal, muslo, hombro, pared torácica, axila, periné, mesenterio, cuello y región glútea. Los pacientes descritos por Evans mostraron una alta tasa de recurrencia local (68\%), metástasis a distancia (41\%), principalmente pulmonares, $\mathrm{y}$ una tasa de mortalidad del $18 \%{ }^{2}$.

Estudios recientes establecen que el SFMBJ tiene un curso clínico menos agresivo, con me- 
nor frecuencia de metástasis a distancia y de recidivas locales ${ }^{3}$, aunque su mejor pronóstico actual puede deberse a que todas estas series clínicas tienen un seguimiento menor y ahora es una entidad bien conocida por los patólogos, lo que permite establecer un diagnóstico preoperatorio y realizar una cirugía más radical disminuyendo el número de recidivas y metástasis precoces ${ }^{2}$.

En la serie de Goodland el al. ${ }^{3}$, se confirmaron las peculiaridades histológicas descritas inicialmente, así como el curso clínico aparentemente benigno de la neoplasia; aunque de los 11 casos que comunica, sólo uno desarrollo metástasis a distancia ${ }^{3}$.

Devaney et al. ${ }^{4}$ comunicaron un caso de una mujer de 17 años que presentó metástasis pulmonares a los 8 años de la extirpación de un nódulo cervical de $1 \mathrm{~cm}$. Nichols y Cooper ${ }^{5}$ presentaron el caso de un varón de 52 años con un SFMBJ en el brazo con positividad para la tinción de Vimentina y CD 34 positivo, lo que permitió excluir los diagnósticos de fibromatosis, fascitis nodular, y fibrosarcoma.

El SFMBJ es un tumor de partes blandas de localización profunda, que aparece más frecuentemente en adultos jóvenes y con ligero predominio en varones ${ }^{2}$. La localización superficial es menos frecuente y se correlaciona con una tasa inferior de metástasis y mortalidad. Macroscópicamente, la neoplasia es un tumor circunscrito de bordes bien definidos (seudocápsula) y con una superficie de corte amarillo grisáceo, firme y fibrosa, que contiene áreas mixoides focales ${ }^{1-5}$. Desde el punto de vista histológico, está constituido por fibroblastos sin signos de atípia dispuestos en forma de remolinos.

Hoy en día se puede afirmar que la evolución de este tumor es lenta, pero a veces mortal debido a su potencial metastatizante y al eventual desarrollo de recidivas locales con el paso de los años. A pesar de ello, se han descrito casos de supervivencia de 50 años del diagnóstico inicial, como sucedió en un paciente con recidiva local y metástasis pulmonares ${ }^{4}$.

Tras la revisión de la literatura, el tratamiento de elección del SFMBJ es la cirugía ${ }^{1-5}$, que constituye la principal forma de tratamiento capaz de modificar la evolución natural de la en- fermedad; incluso en recurrencias primarias y subsiguientes, así como de las metástasis. El tratamiento es la resección amplia con márgenes de seguridad de $2-3 \mathrm{~cm}$. siempre que sea posible, aunque se han descrito casos con buena evolución tratados con resección marginal a través de la seudocápsula, aún con invasión de los márgenes quirúrgicos ${ }^{6}$. El papel de la quimioterapia y radioterapia no ha sido establecido claramente en la literatura, no pudiéndose realizar estudios seriados por su baja frecuen$c^{4}{ }^{4}$. La escisión de las lesiones grandes ( $>5$ $\mathrm{cm}$.) o con márgenes quirúrgicos contaminados debería ir seguida con la irradiación con haz externo; mientras que las pequeñas que pueden escindirse ampliamente pueden no requerir radiación coadyuvante ${ }^{4-6}$. La quimioterapia puede tener un beneficio en la supervivencia e incrementar el intervalo libre de enfermedad en pacientes bien seleccionados ${ }^{4}$, como serían pacientes con lesiones grandes no resecables para reducir el tamaño tumoral y en pacientes con enfermedad diseminada junto con la cirugía de resección de nódulos pulmonares ${ }^{4}$.

Hasta la década de los setenta, el tratamiento primario de los sarcomas de partes blandas en las extremidades era la amputación. En el SFMBG la amputación no ha demostrado ser superior a la cirugía de resección en términos de recurrencia, desarrollo de metástasis y mortalidad, aun cuando el papel de la radio y quimioterapia sea controvertido y exista discusión sobre su uso ${ }^{4}$. Cuando la extirpación del tumor se realiza de forma precoz y con unos márgenes quirúrgicos adecuados, los resultados obtenidos con la cirugía, en términos de control local y sistémico de la enfermedad, son idénticos a los objetivados con la amputación del miembro. Estos márgenes son variables según autores, para algunos el mismo que cualquier sarcoma de partes blandas, 2-3 cm., para otros basta una resección marginal con márgenes libres ${ }^{1-6}$. A pesar de todo, la amputación se indica todavía en un $10 \%$ de los casos, bien sea por no funcionalidad del miembro preservado, por infección, fracaso de la reconstrucción vascular o enfermedades concomitantes (enfermedad vascular periférica) ${ }^{6}$.

En la revisión de la literatura no hemos podido encontrar ningún tumor de Evans de loca- 
lización en la mano, siendo pues el caso presentado el primero del que tenemos conocimiento. Apoyados en el diagnóstico previo de tumor mesenquimal benigno se decidió realizar una exéresis marginal, no administrando radioterapia postoperatoria tras el diagnóstico definitivo al tratarse de una lesión de bajo grado de malignidad, pequeña, superficial y con márgenes quirúrgicos libres de enfermedad, encontrándose el paciente libre de enfermedad al año, aunque es necesario un mayor tiempo de seguimiento.

\section{BIBLIOGRAFÍA}

1. Evans HL. Low-grade fibromyxoid sarcoma, a report of two metastasizing neoplasms having a deceptively benign appearance. Am J Clin Pathol, 1987; 88: 615-9.

2. Evans HL. Low-grade fibromyxoid sarcoma. A report of $12 \mathrm{ca}$ ses. Am J Surg Pathol, 1993; 17: 595-600.

3. Goodland JR, Mentzel T, Flet- cher CDM. Low-grade fibromyxoid sarcoma: clinicopathological analysis of eleven new cases in support of a distinct entity. Histophatology, 1995; 26: 229-37.

4. Devaney DM, Dervan P, O'Neill $\mathrm{S}$, et al. Low-grade fibromyxoid sarcoma. Histophatology, 1990; 17: 463-5.

5. Nichols GE, Cooper PH. Low- grade fibromyxoid sarcoma: case report and inmunohistochemical study. J Cutan Pathol, 1994; 21: 356-62.

6. Ballesteros-Pomar M, Fernández-Samos R, Martín-Álvarez A, et al. Extirpación de sarcoma fibromixoide de bajo grado con resección y reconstrucción de arteria femoral. Angiología, 2005; 57(4): 345-51. 